\title{
Vibration Damping Optimization using Simulated Annealing Algorithm for Vehicle Powertrain System
}

\author{
Mehmet Onur Genc \\ Research and Development Center \\ Valeo Automotive Systems \\ Bursa, Turkey \\ mehmet-onur.genc@valeo.com
}

\author{
Necmettin Kaya \\ Mechanical Engineering Department \\ Bursa Uludag University \\ Bursa, Turkey \\ necmi@uludag.edu.tr
}

\begin{abstract}
The clutch system in a vehicle's powertrain system controls torque transmission and has vibration damping properties. A vehicle's clutch system is subjected to high dynamic loads and vibrations, under operational conditions, that need further system analysis. The torque generated from the vehicle's engine creates vibrations at different levels of frequencies. For this purpose, vibration damping systems have to be designed to make the vehicle work more efficiently. In this study, the 1-D modeling of powertrain system, including metallic clutch damper springs, was subjected to vibration optimization with the Simulated Annealing (SA) algorithm. This novel methodology accelerates the powertrain system vibration optimization and provides assumptions eliminating cost and time in real vehicle testing.
\end{abstract}

Keywords-clutch damper; simulated annealing; 1-D modeling; damper torque; powertrain system; driving comfort; vibration

\section{INTRODUCTION}

Clutch damper springs, used in vehicle powertrain systems, are of great importance as they damp engine vibrations during torque transmission (Figure 1). Prominent studies have been carried out on the optimization of the vibration on vehicles. Torsional mode analysis was carried out in [1] investigating the modeling of powertrain systems, including automated transmission. The hydraulic hybrid powertrain system was analyzed in [2] using 1-D modeling. Analysis using 1-D simulation at stiffness levels of the clutch disc damper were studied in [3]. The natural frequency of vehicle components were studied in [4], assuming on optimal weight values. In [5], an analysis on the vibration frequency level of a 3-cylinder engine proposed improvements to the clutch design. The study of a passenger car's powertrain system modeling determined the clutch damper disc stiffness behavior on driving conditions in [6]. The frequencies of the gearbox vibrations on different gearbox types were analyzed in [7], while in [8] the engine vibrations were analyzed by FFT method. Harmonic investigations were performed on an engine's behavior in [9], in order to reduce the noise in the power transmission system. The design of transmission gears and the optimization of clutch-damping factors, by applying harmonic analysis, were studied in [10]. The frequency ranges on heavy vehicles were examined by modal analysis in [11]. Optimization algorithms are of high importance in vehicle engineering system design.
The integrated Genetic Algorithm (GA) was used in [12] in order to provide optimized frequency levels on an electric engine powertrain. Simulated Annealing (SA) algorithm was used in [13] for the optimization of a machine tool movement during production cycles. The constrained and unconstrained shape optimization of cold-formed steel columns was examined in [14]. In [15], a logarithmic cooling schedule of the SA algorithm was studied in order to improve global searchability. The optimization of pneumatic clutch activator's system behavior, by using the SA algorithm, was studied in [16]. The penalty added SA algorithm for constrained flow problems was examined in [17], while various penalty functions and their integration into the SA algorithm were studied in [18].

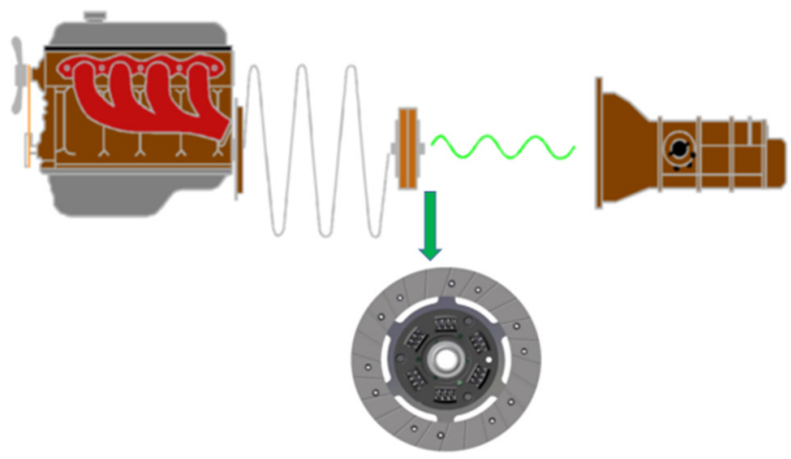

Fig. 1. Clutch system dampening effect

This study examines the powertrain system of a gasoline engine vehicle, having $110 \mathrm{Nm}$ torque, integrating the Simulated Annealing (SA) algorithm into powertrain system vibration optimization simultaneously with 1-D modeling, providing assumptions and precautions prior to production phases.

\section{ClutCH DAMPER SYSTEM}

Clutch damper systems are designed to damp excessive vibration transmission from engine to gearbox. The clutch damper disc can be observed in detail in Figure 2. Metallic damper springs, located in the clutch disc, enable damping under driving conditions. Damper spring's stiffness value is the sum of the stiffness of each spring ( $\left.\mathrm{k}_{\text {equivalent }}\right)$. The importance 
of the stiffness behavior can be observed on the model analysis of the powertrain system [6]. Damper torque is applied on the clutch disc to get damper torque capacity which has high importance on the powertrain system optimization. Damper torque's graph indicates an hysteresis, due to the internal friction which has effect on the dampening ability (Figure 3 ). Figure 4 shows the loading and unloading phases of the clutch damper disc in operational condition. In this study, the clutch disc assembly can be compressed up to $6.5^{\circ}$ radial travel.

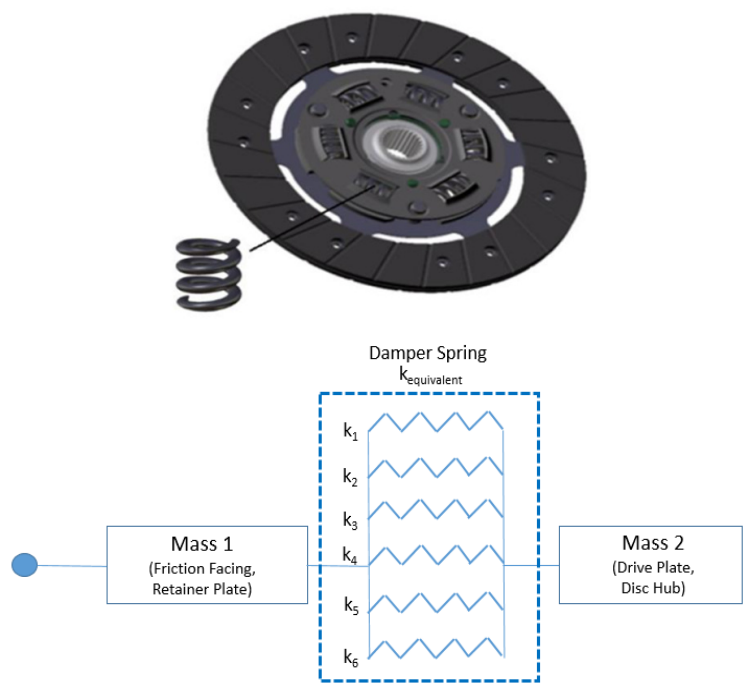

Fig. 2. Clutch disc modeling

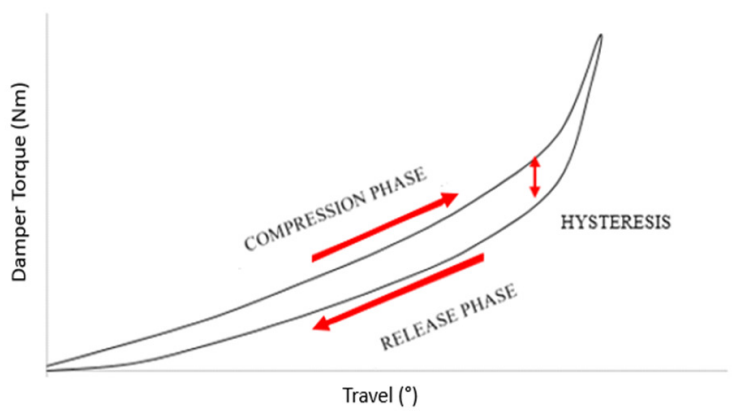

Fig. 3. Clutch disc damper torque - Torque $(\mathrm{Nm})$ vs. Angle $\left(^{\circ}\right)$
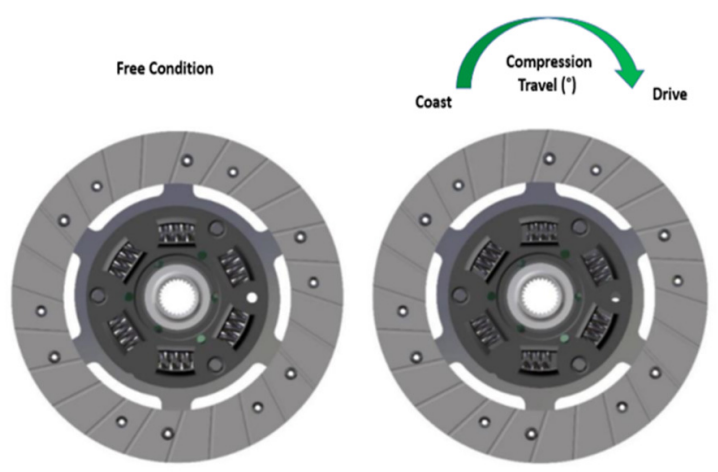

Fig. 4. Clutch damper disc operation behavior

\section{MODELING OF THE POWERTRAIN SYSTEM}

The powertrain system model belongs to a specific type of passenger vehicle. Simcenter AMESim was utilized to analyze the model (Figure 5). The metallic spring was selected from the library of AMESim. The stiffness value $16 \mathrm{Nm} /{ }^{\circ}$, according to the results of experimental disc measurements, was provided as input to the model interface (Figure 6). Figure 7 contains the sample output graph for the analyzed 1-D modeling. The vibration was taken from the gearbox model part. The selected values on this graph were used for the vibration optimization using the SA algorithm integrated in AMESim. The gearbox in the powertrain system is important in displaying the dampening effects of the clutch system. In case the target dampening is not obtained from the clutch system, mechanical damages may occur in the powertrain system.

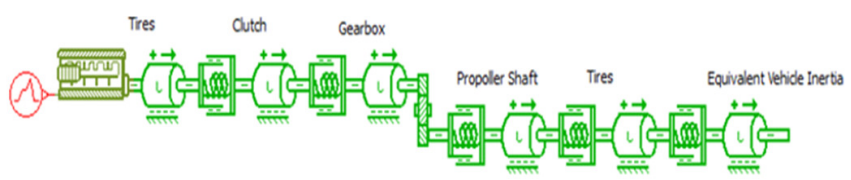

Fig. 5. 1-D modeling of vehicle powertrain system

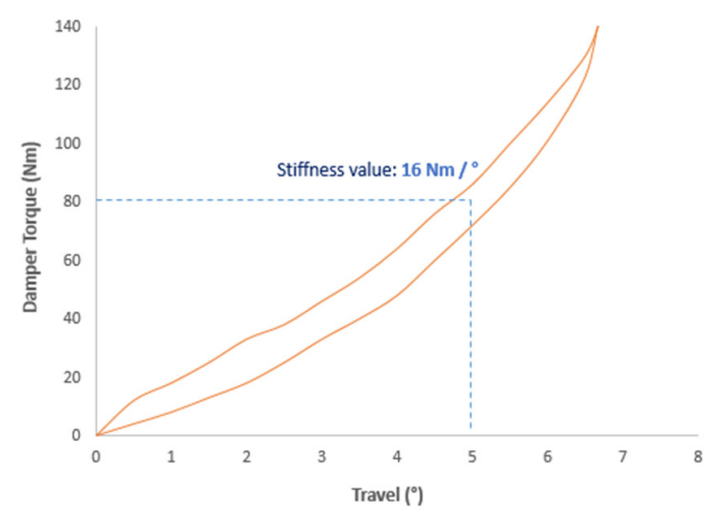

Fig. 6. Damper torque of clutch damper disc used in the analysis

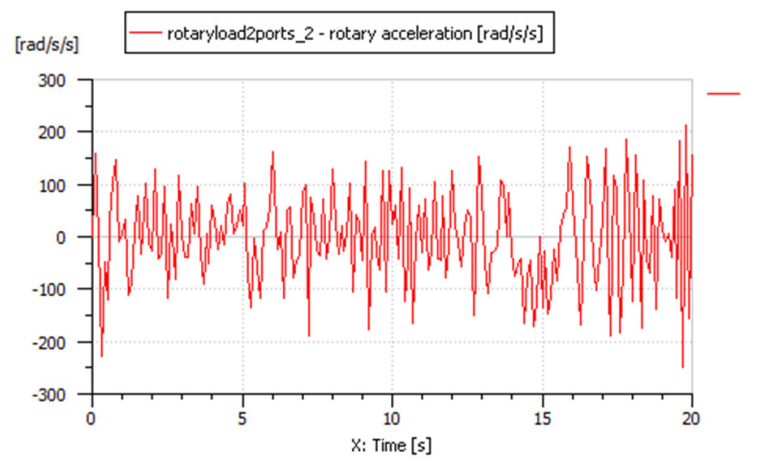

Fig. 7. Vibration analysis results on gearbox

\section{SA ALGORITHM INTEGRATED WITH 1-D MODELLING}

SA algorithm is designed to perform a global search, preventing the convergence to locally optimal solutions, by allowing movement to the worst solutions through the Boltzmann factor, simulating the annealing process of metals. 
Its name comes from the simulating the behavior of metals in the annealing process, in which the metal is heated and kept at stabilized temperature while slowly cooling The optimization process starts by generating a random initial solution, while SA allows movement resulting in solutions that are worse (uphill moves) than the current solution in order to escape from local minima. Each iteration of a new current solution leads to the decrease of the current temperature in the ratio of $k$ which is called cooling rate (1):

$$
T_{\text {new }}=k * T_{\text {current }}
$$

Uphill moves eliminate each local minimum, while the Boltzmann probability factor enables the algorithm to take worst results in the range of the Boltzmann probability equation, while the global minimum is searched and finally found.

$$
\text { Boltzmann factor }=1 /\left(e^{\left(\frac{f\left(\overline{x_{t m p}}\right)-f\left(\overrightarrow{x_{l}}\right)}{T_{t}}\right)}\right)
$$

The optimization is performed by a system programmed in Python integrating the SA algorithm and AMESim analysis. Figure 8 shows the process of each main iteration. Figure 9 describes the algorithm of the Python script. At first, the function code of the AMESim 1-D modeling is defined. Then, SA algorithm is called, with a penalty function defining the stiffness constraint which is defined by taking into consideration the geometrical limits of the clutch damper disc. The stiffness value was defined as: $15.5 \leq \mathrm{x} \leq 16.5$.

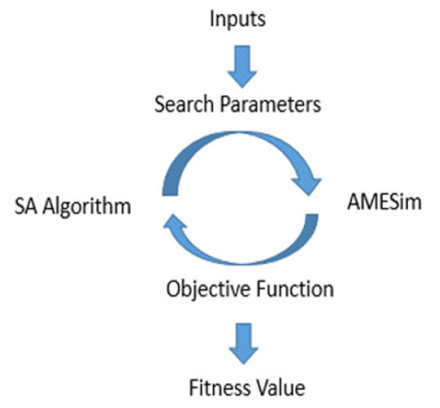

Fig. 8. Python script integrating AMESim and SA algorithm

1 Define AMESim function run code

2 Initialize $\rightarrow X_{0}, T_{0}, k, N, M$,

3 Call AMESim function and calculate $F_{\text {Initial }}$ with $X_{0} \leftarrow F$ Objective initial function

4 for $i=1$ : Max Iteration

5 Construct a neighbor solution randomly $\left(\mathrm{X}_{0} \longleftrightarrow \mathrm{X}_{\mathrm{New}}\right)$

6 Call AMESim function and calculate $\mathrm{F}_{\mathrm{New}}$ with $\mathrm{X}_{\mathrm{New}}$ from AMESim

7 If $\mathrm{F}_{\mathrm{New}}<\mathrm{F}_{\mathrm{n}}$

$8 \mathrm{Xn} \leftarrow \mathrm{X}_{\mathrm{New}}$

9 If $\mathrm{F}_{\mathrm{New}}<\mathrm{F}_{\mathrm{Best}}$

$10 \mathrm{X}_{\mathrm{New}} \leftarrow \mathrm{X}_{\text {Best }}$

11 Calculate penalty parameters for given constraint $\left(\mathrm{X}_{\mathrm{c}}\right)$

12 else if penalty $>$ random $(0,1)$

$13 \mathrm{Xn} \leftarrow \mathrm{X}_{\mathrm{New}}$

14 Calculate penalty parameters for given constraint $\left(X_{c}\right)$

15 End

$16 \mathrm{~T}=\mathrm{T} * \mathrm{k}$

17 Output: $\mathrm{F}_{\text {Best, }} \mathrm{X}_{\text {Best }}$

Fig. 9. AMESim integrated SA algorithm
Figure 10 presents the SA algorithm's flowcart in detail. Spring stiffness value defines the initial search parameter and SA algorithm parameters such as temperature $T$, cooling ratio $k$ and iteration parameters are entered into the algorithm. At the end of the algorithm the best value of $F_{\text {best }}, X_{\text {best }}$ is obtained.

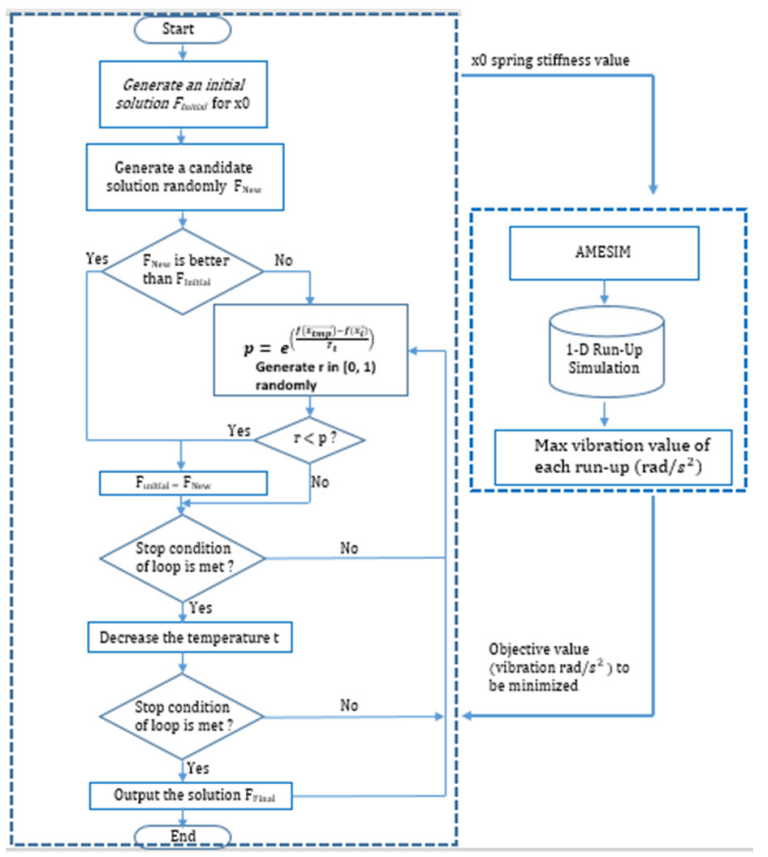

Fig. 10. SA algorithm - vibration minimization through SA and AMESim

\section{Simulation RESUlts}

Table I shows the obtained minimum vibration results on the gearbox. X represents the clutch damper stiffness level and optimum vibration values for each run are exhibited.

TABLE I. OPTIMIZATION RESULTS

\begin{tabular}{|c|c|c|c|c|c|}
\hline & Run 1 & Run 2 & Run 3 & Run 4 & Run 5 \\
\hline $\mathbf{X ~ ( N m / { } ^ { \circ } )}$ & 15.749 & 15.854 & 15.801 & 15.715 & 15.732 \\
\hline Objective Function (rad/s $\left.^{2}\right)$ & 86 & 92 & 89 & 84 & 85 \\
\hline
\end{tabular}

The result values of each run were very close. Figure 11 shows the graph of the objective function and temperature for an example run. It seems that SA algorithm successfully eliminates local minima and converged to the global minimum point at each run. Moreover, Figure 11 also shows the vibration decrease. The optimum damper stiffness was $15.715 \mathrm{Nm} /{ }^{\circ}$. SA algorithm inputs have many effective parameters to change search capability. Table II shows a brief vibration result comparison obtained from the 1-D modeling. The base clutch disc design, having $16 \mathrm{Nm} /{ }^{\circ}$ damper stiffness value, resulted in $105 \mathrm{rad} / \mathrm{s}^{2}$ on the gearbox utilizing the AMESim program. Conversely, the optimum stiffness value $15.715 \mathrm{Nm} /{ }^{\circ}$ resulted in $84 \mathrm{rad} / \mathrm{s}^{2}$ on the gearbox showing a decrease of about $21 \%$. The result analysis values are directly linked to the key parameters of the SA algorithm. Therefore, in case the key parameters of the algorithm change, the obtained values are expected to change. This case needs detailed analysis in SA algorithm parameter variations. 


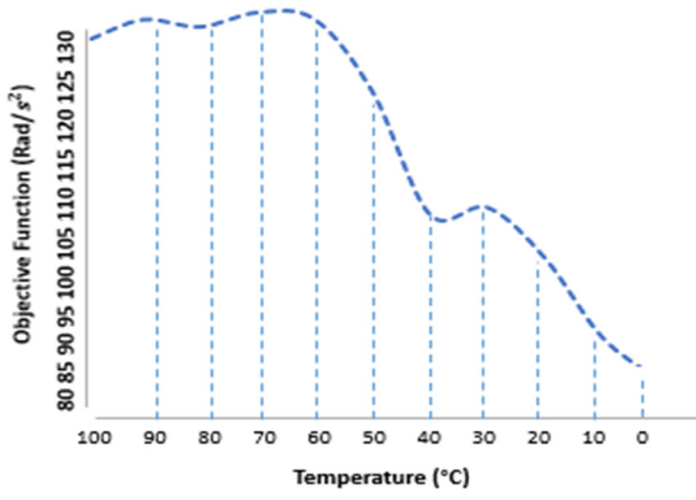

Fig. 11. SA algorithm: Objective function vs temperature graph

TABLE II. COMPARISON RESULTS OF BASE VS OPTIMUM DESIGN

\begin{tabular}{|c|c|c|}
\hline & Base design & Optimum design \\
\hline $\mathbf{X}\left(\mathbf{N m} /{ }^{\circ}\right)$ & 16 & 15.715 \\
\hline Objective Function $\left(\mathbf{r a d} / \mathbf{s}^{2}\right)$ & 105 & 84 \\
\hline
\end{tabular}

\section{CONCLUSIONS}

This study analyzed and evaluated the vibration damping optimization of a vehicle's powertrain system, designed for a middle segment vehicle having an $110 \mathrm{Nm}$ torque gasoline engine. Excessive vibrations are making the driving experience uncomfortable, while unwanted oscillations result in mechanical damages. New generation optimization algorithms approach optimum values, providing optimum key parameters for the system. For this purpose, a new methodology was presented in order to find optimum design parameters that reduce the vibration level. The SA algorithm was developed and used with 1-D modeling for torsional vibration optimization. Vibrations in the gearbox were decreased by $21 \%$, using the optimum clutch damper spring stiffness value. This method saves cost and time on the optimization of the vibration dampening in a powertrain system.

\section{ACKNOWLEDGMENT}

This study was conducted with the collaboration of Valeo Automotive Systems and Bursa Uludag University.

\section{REFERENCES}

[1] S. J. Hwang, J. S. Chen, L. Liu, C. C. Ling, "Modelling and simulation of a powertrain-vehicle system with automatic transmission", International Journal of Vehicle Design, Vol. 23, No. 1, pp. 145-160, 2006

[2] A. Macor, A. Benato, A. Rossetti, Z. Bettio, "Study and simulation of a hydraulic hybrid powertrain”, Energy Procedia, Vol. 126, pp. 11311138,2017

[3] M. O. Genc, N. Kaya, "Modelling and experimental investigation of clutch damper spring stiffness on truck driving comfort", International Journal of Advances on Automotive and Technology, Vol. 1, No. 2, pp. 121-136, 2018

[4] R. Smith, "Changing the effective mass to control resonance problems", Sound and Vibration, Vol. 35, No. 5, pp. 14-17, 2001

[5] H. Acar, C. Gul, M. Avci, "Clutch disc torsional characteristics optimization to reduce idle and gear rattle on passenger car", International Automotive Congress, Belgrade, Serbia, April 14-15, 2015
[6] M. O. Genc, B. Budak, N. Kaya, "Modelling and vibration analysis of powertrain systems", International Journal of Automotive Science and Technology, Vol. 2, No. 1, pp. 17-25, 2018

[7] M. Sofian, D. Hazry, K. Saifullah, M. Tasyrif, K. Salleh, I. Ishak, "A study of vibration analysis for gearbox casing using finite element analysis", International Conference on Applications and Design in Mechanical Engineering, Batu Ferringhi, Penang, Malaysia, October 1113, 2009

[8] A. Brandt, T. Lago, K. Ahlin, J. Tuma, "Main principles and limitations of current order tracking methods", Sound and Vibrations, Vol. 39, No. 3, pp. $19-22,2005$

[9] C. S. Keeney, S. Shih, "Prediction and control of heavy duty powertrain torsional vibration", SAE Transactions, Vol. 101,pp. 805-814, 1992

[10] S. Jadhav, "Powertrain NVH analysis including clutch and gear dynamics", SAE Technical Paper 2014-01-1680, SAE, 2014

[11] A. Mazzei, B. Alzahabi, L. K. Natarajan, "Analysis of the drivetrain bending response for a heavy truck driveline", SAE Technical Paper Series, 2012

[12] K. Soleimani, J. Mazloum, "Designing a GA-based robust controller for Load Frequency Control (LFC)", Engineering, Technology \& Applied Science Research, Vol. 8, No. 2, pp. 2633-2639, 2018

[13] A. A. Afifi, W. A. Khan, D. R. Hayhurst, "Adaptation of the simulated annealing optimization algorithm to achieve improved near-optimum objective function values and computation times for multiple component manufacture", International Journal of Advanced Manufacturing Technology, Vol. 60, No. 5-8, pp. 437-451, 2012

[14] J. Leng, Z. Li, J. K. Guest, B. W. Schafer, "Shape optimization of coldformed steel columns with fabrication and geometric end-use constraints", Thin-Walled Structures, Vol. 85, pp. 271-290, 2014

[15] W. Shao, G. Guo, "Multiple-try simulated annealing algorithm for global optimization", Mathematical Problems in Engineering, Vol. 2018, article ID 9248318, 2018

[16] M. G. Skarpatis, F. N. Koumboulis, A. S. Ntellis, "Robust control of pneumatic clutch actuators using simulated annealing techniques", $21 \mathrm{st}$ Mediterranean Conference on Control and Automation, Chania, Greece, June 25-28, 2013

[17] X. Q. Yang, A. I. Mees, K. Campbell, "Simulated annealing and penalty methods for binary multicommodity flow problems", Progress in Optimization, Vol. 39, pp. 93-105, 2000

[18] C. Park, J. H. Moon, "A penalized principal component analysis using simulated annealing", Communications for Statistical Applications and Methods, Vol. 10, No. 3, pp. 1025-1036, 2003 